\title{
Cognitive health begins at conception: addressing dementia as a lifelong and preventable condition
}

\author{
Jennifer H Barnett ${ }^{1,2^{*}}$, Vladimir Hachinski ${ }^{3}$ and Andrew D Blackwell ${ }^{1,2}$
}

\begin{abstract}
Background: Dementia is a major public health problem that poses an increasing burden on the health and wealth of societies worldwide. Because the efficacy of current treatments is limited, increasing efforts are required to prevent the diseases that cause dementia.

Discussion: We consider the evidence that lifelong prevention strategies may be an effective way to tackle the national burden of dementia in the absence of a cure. The links between lifestyle and cardiovascular disease are widely understood and accepted, but health professionals and patients remain unconvinced about the extent to which risk for dementia can be modified. However, there is strong evidence that at least half of risk for dementia is attributable to lifestyle factors such as diet, exercise and smoking. Moreover, the disease processes that result in dementia develop over several decades, implying that attempts to ameliorate them need to start early in life. Some modifiable risk factors for dementia act from the earliest stages of life, including in utero.
\end{abstract}

Summary: Rebalancing efforts from the development of treatments to increased emphasis on prevention may be an alternative means to reducing the impact of dementia on society.

Keywords: Dementia, Alzheimer's disease, Prevention, Epidemiology

\section{Background}

Worldwide, 36 million people suffer from dementia, costing an annual US\$600 billion [1]. Dementia is a clinical state due to one of several underlying pathologies, most commonly Alzheimer's disease (AD) or cerebrovascular disease, with more rare causes including dementia with Lewy bodies and frontotemporal dementia [2]. Conclusively diagnosing which of these diseases is present in an individual is only possible post mortem, so in clinical practice, patients are ascribed a probable differential diagnosis and then treated accordingly. In reality, both post mortem [3-5] and brain imaging studies [6,7] show that many, and perhaps most, patients diagnosed with either Alzheimer's or vascular dementias are in fact experiencing the cumulative effects of both pathologies. Moreover, cerebrovascular

\footnotetext{
*Correspondence: jhb32@cam.ac.uk

'Department of Psychiatry, University of Cambridge, Cambridge Biomedical Campus, Cambridge, CB2 2QQ, UK

${ }^{2}$ Cambridge Cognition Ltd, Tunbridge Court, Tunbridge Lane, Bottisham, CB25 9TU, UK

Full list of author information is available at the end of the article
}

disease appears to act synergistically with Alzheimer's pathology to worsen the cognitive performance of the patient $[3,8]$, lowering the threshold at which the symptoms of dementia emerge.

To an individual patient, accurate differential diagnosis matters only to the extent that it provides the most accurate prognosis, and triggers the most effective treatment course. Unfortunately, at present there are no licensed treatments for vascular dementia, and available AD treatments bring only short-term relief, typically slowing the worsening of symptoms for 6 to 12 months. Recent efforts to develop new drugs to treat symptoms, or to slow disease progress, have been disappointing, and after some high-profile failures [9-11] there is a growing concern that the pharmaceutical industry may reduce investment in the field. If effective and affordable pharmacological or biological treatments do not emerge, preventing the diseases that cause dementia will become ever more important.

While the links between lifestyle and cardiovascular disease are widely accepted, considerable fatalism exists

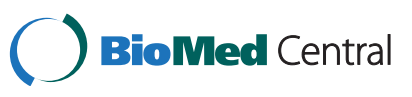


among both health professionals and patients about the extent to which risk for dementia can be modified. Consequently, it is timely to recall that around half of risk for dementia is attributable to lifestyle factors such as diet, exercise and smoking and that this risk is accrued throughout life, so attempts to ameliorate risk need to start early. Indeed there is growing evidence that modifiable risk factors for dementia act from the earliest stages of life, including in utero.

\section{Discussion}

\section{Dementia is largely preventable}

Age is the biggest risk factor for dementia, with risk for both $\mathrm{AD}$ and vascular dementia $(\mathrm{VaD})$ doubling every 5 years over $65[1,12]$. Late-onset $\mathrm{AD}$ and $\mathrm{VaD}$ are both moderately heritable and although most individual genes increase risk by only a small amount, the apoliprotein $\mathrm{E}$ (APOE) $\varepsilon 4$ allele confers a threefold to four fold increase in risk for $\mathrm{AD}$ [13] and a more modest increase in $\mathrm{VaD}$ [14]. Men are at higher risk for $\mathrm{VaD}$, and women for $\mathrm{AD}$, alongside people with a history of head injury.

Against this background of non-modifiable risk, many preventable factors considerably exacerbate an individual's risk (see Figure 1). Risk factors for VaD are those associated with general cardiovascular health, and three-quarters of patients with $\mathrm{VaD}$ and more than half of those with vascular cognitive impairment have a history of stroke, compared with only $5 \%$ to $7 \%$ of people with $\mathrm{AD}$ [15]. Half of AD risk is explained by seven lifestyle-related factors: diabetes, hypertension, obesity, smoking, depression, cognitive activity/education and physical activity [16]. Evidence is particularly strong for a cluster of metabolic factors including hypertension, serum lipids, diabetes, and obesity, and exposure to these factors during midlife (as opposed to late life) seems particularly predictive of later dementia risk [17-20].

Importantly, the protective effects of healthy lifestyles are as great for dementia as for other late-life diseases.
Prospective cohort studies show that individuals who adhere to a Mediterranean-style diet experience a greater reduction in risk for diseases such as dementia, Parkinson's and stroke (overall RR $=0.87$ (95\% CI 0.81 to 0.94$)$ ) than the reduction in risk seen for cardiovascular disease $(\mathrm{RR}=0.90$ (95\% CI 0.87 to 0.93$)$ ), cancer $(\mathrm{RR}=0.94$, $(95 \%$ CI 0.92 to 0.96$)$ ), or overall mortality ( $R R=0.92(95 \%$ CI 0.90 to 0.94 ) [21]). Similarly, meta-analyses of the effects of physical exercise suggest that it can reduce risk for $\mathrm{AD}$ by $45 \%$ (RR 0.55 (95\% CI 0.36 to 0.84 ) [22]), a protective effect comparable to that achieved against type II diabetes (RR 0.63 (95\% CI 0.49 to 0.79 ) [23]), or coronary heart disease (RR 0.73 (95\% CI 0.66 to 0.80) [24]). The effects of reducing modifiable risk may be particularly dramatic in individuals at high non-modifiable risk. For example, in the Honolulu study, relative risk for impaired cognition was 13 among individuals with both the APOE $\varepsilon 4$ allele and hypertension, but was reduced to just 2 by effective hypertension treatment [25]. Similarly, the amyloid deposition associated with APOE $\varepsilon 4$ carrier status has recently been shown to be exacerbated by hypertension and reduced by treatment to control blood pressure [26]. Those who are at highest a priori risk for dementia are, by the same token, most likely to benefit from strategies to reduce modifiable risk factors.

A major barrier to implementing effective prevention strategies for dementia is that the risk-modifying behaviors identified in observational studies have rarely been replicated in randomized clinical trials. Secondary prevention for $\mathrm{VaD}$, for example using angiotensin-converting enzyme (ACE) inhibitors, can significantly prevent further strokes and subsequent cognitive decline [27]. However, studies aiming to prevent dementia among the general elderly population, or to prevent worsening of symptoms among individuals with dementia, have mostly failed. These include trials of non-steroidal anti-inflammatory drugs (NSAIDs) [28] and vitamin E [29], and interventions for low folate and vitamin B12 [30]. This pattern of failure
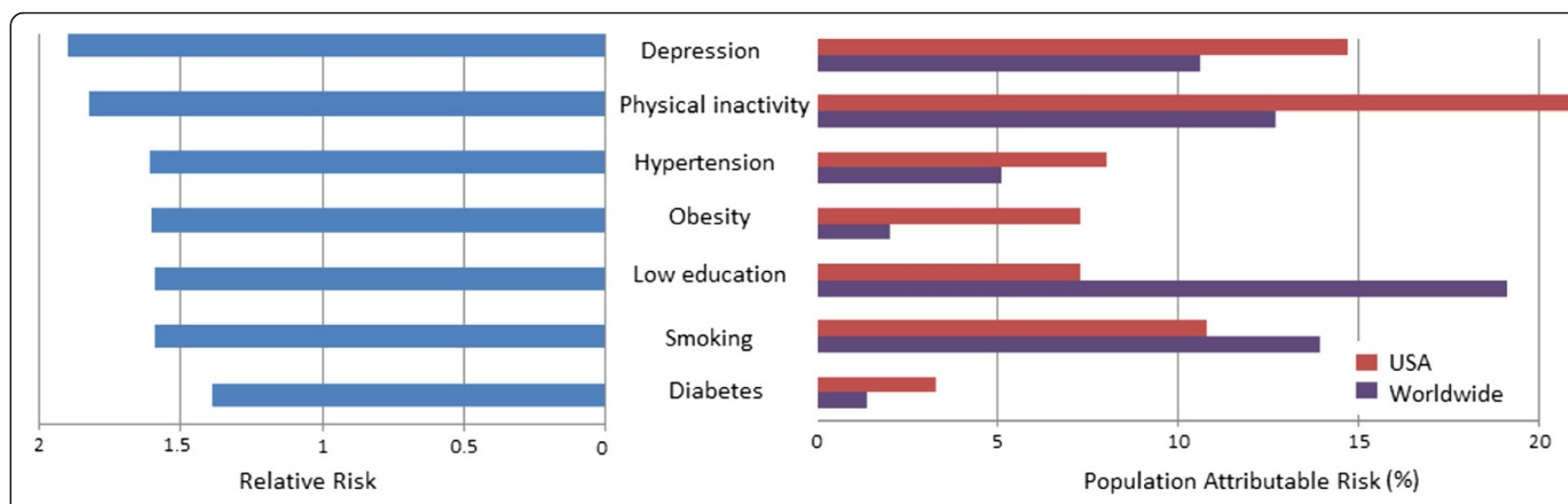

Figure 1 Relative and population attributable risk estimates for seven modifiable risk factors for Alzheimer's disease (data from Barnes and Yaffe [16]). 
to turn promising observations into successful interventions may reflect the effect on observational studies of reverse causality; for example, individuals experiencing the early stages of cognitive decline are probably less likely to eat well and take part in physical activity. Associations between risk factors and dementia may also be confounded by other behavioral factors, personality, and comorbid conditions. One particularly plausible explanation is that the failure of these trials simply means that attempts to prevent dementia need to start earlier, and last longer, than any so far conducted.

\section{Dementia risk begins at birth}

Both $\mathrm{AD}$ and $\mathrm{VaD}$ are the result of disease processes which usually develop over several decades. While the evidence for association between lifestyle factors and dementia risk is strongest for exposure in midlife, lifestyles in middle age usually reflect lifelong patterns of behavior, so individuals who eat well and exercise in midlife are likely to be benefiting from the cognitively protective effects of a lifetime of such behaviors. For many adult diseases, substantial risk can be traced to early childhood and, in some cases, back to the womb. The 'Barker hypothesis' that suboptimal prenatal and early life environment increases risk for adult disease, has been convincingly demonstrated for conditions including stroke, heart disease, insulin resistance, and hypertension [31]. Although considerably less research has addressed this, there are a number of ways in which this is probably also true for dementia. Neonatal environment, particularly diet, can have a major impact on the development of cognitive function. Breastfeeding confers an IQ advantage [32], and in vulnerable groups such as premature babies, optimal nutrition in the first few weeks can improve cognitive and brain development throughout childhood and adolescence [33], and low birthweight babies show poorer cognitive development, and poorer cognitive function even as adults [34].

General indices of early development, such as limb length [35] are also associated with risk for dementia. People who have no symptoms of dementia despite significant $\mathrm{AD}$ pathology on autopsy tend to have larger brains and a greater number of neurons than those with no AD pathology [36]. Optimal physical growth in the brain thus seems to confer some resilience to the effects of $\mathrm{AD}$ pathology and neurodegeneration.

Some environmental effects may act directly on the developing brain, for example through prenatal exposure to toxins. Routes that are more indirect are also likely: for example, maternal smoking may increase later risk for dementia by influencing lifelong cardiovascular and metabolic health [37]. Similarly, an individual who is obese in midlife (with a body mass index $\geq 30$ ) has an approximately doubled risk for later $\mathrm{AD}$, while an individual who is overweight (body mass index (BMI) between 25 and 30) has a $35 \%$ increased risk [38]. But midlife obesity is itself significantly driven by early life: both high and low birthweight babies are at increased risk for later obesity [39].

Lifetime associations between cognition and health may also operate through behavioral choices. In a New Zealand birth cohort, childhood self-control, an executive function dependent on prefrontal cortical integrity, predicted a range of adult physical health outcomes [40] including metabolic status, periodontal disease, and drug and tobacco dependence. Some of the relationship between self-control and later health was explained by the approximately doubled likelihood of children with poor self-control experiencing common adolescent 'snares', such as starting smoking at an early age.

Optimizing the cognitive health of individuals and societies Throughout life, many potentially treatable or reversible causes of cognitive impairment can occur. Among children, disorders such as attention deficit hyperactivity disorder (ADHD) and dyslexia impair specific cognitive functions that can considerably impact a child's educational attainment. Among adults, reversible causes of cognitive impairment can include stress, sleep deprivation, drug and alcohol use, depression, thyroid disease, and vitamin deficiencies. If not detected, these conditions may have long term consequences for cognitive health, including structural or functional brain changes that may be minimized by early treatment.

Individuals with greater educational and occupational attainment, those with higher IQ, and those who undertake complex mental activity later in life are all at lower risk of dementia, and show slower cognitive decline after a diagnosis of dementia [41]. The idea that dementia can be prevented through interventions such as 'brain training' programs has captured the public imagination. It is estimated that consumers spent around US\$500 million on such products in 2012 [42] though little evidence supports their benefits among healthy elderly individuals.

Functioning at a suboptimal cognitive level at any point in the lifespan may reduce engagement in activities which protect brain health, including education, employment, and healthy lifestyles. A child with undetected dyslexia is unlikely to undertake higher education, a young adult with poor concentration is unlikely to rise through the career ranks, and an older person with a depression-induced memory complaint is unlikely to take part in cognitively challenging activities. To maximize the cognitive health of the population it is therefore important that cognitive function is monitored throughout life, so that any changes can be detected and, where appropriate, treated.

\section{Turning epidemiology into prevention}

The epidemiological evidence described above provides strong evidence of associations between lifestyle factors 
and risk for dementia but these associations do not prove causality. Nonetheless, the existence of these associations does suggest that some risk for dementia could be reduced through the protection of cognitive health throughout the lifespan (Figure 2). Strategies might include the optimizing of diet through neonatal periods as well as later in life, further reducing behaviors such as smoking, which may be directly or indirectly harmful to cognitive health, and the early detection and treatment of reversible causes of cognitive impairment throughout life.

Public policy impacts dementia risk in a number of ways. Many countries now have national dementia strategies and aim to increase research capacity as well as increasing public awareness. Given the potential burden of dementia on society, it should be a public health priority to educate both clinicians and the population to understand that risk for dementia is driven by lifestyle choices as well as genetic predisposition. Using an internet-based survey, we recently asked more than 1,000 UK general practitioners (GPs) whether a person could alter their risk of developing dementia. While a majority (59\%) agreed they could, 32\% weren't sure and $10 \%$ thought they could not; this is concerning, since both the scientific literature and current clinical practice guidelines [2] unequivocally support the existence of modifiable factors in contributing to dementia risk. Increased training in dementia may be a useful first step: in a separate study, half of English GPs felt they had not received sufficient training to help them diagnose and manage dementia [43].

The modifiable factors that most predict risk for dementia are conditions (obesity, hypertension, diabetes), or lifestyle factors (diet, cognitive and physical activity, smoking cessation) where a GP is best placed to effect change. However moving beyond demonstrating associations to demonstrating causality, efficacy, and ultimately, cost effectiveness is something that only randomized controlled trials can tackle. While small-scale projects do exist in the UK, we lag behind much of Europe where several large-scale prevention initiatives are occurring [44]. These aim to apply the methodological rigor of a randomized controlled trial to multimodal lifestyle interventions among older adults who are not yet demented. They are characterized by large sample sizes, long follow-ups, and an intervention that is typically carried out by nurses or allied health professions, but are limited in that they are intervening only in late life, which may already be too late.
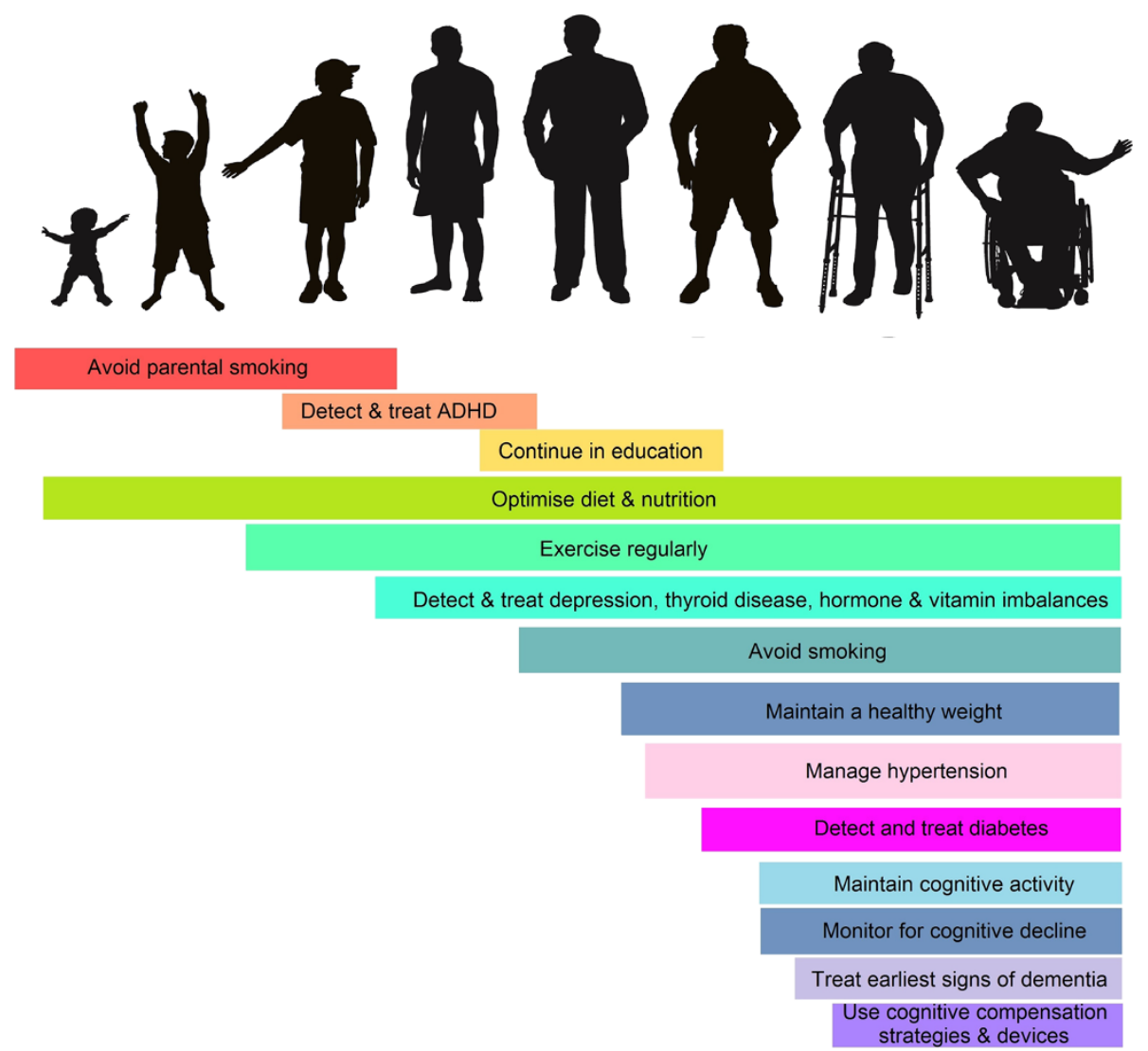

Figure 2 Preventing dementia throughout life. 


\section{Summary}

In recent years, the scientific understanding of dementia has shifted from that of a late-life disease that cannot be prevented to that of a lifelong disease process, where factors such as diet and education impact risk from the earliest stages of life. As yet, there is little evidence from large-scale studies about the efficacy of individual or combined lifestyle interventions in preventing dementia, but in the absence of disease-modifying therapies, the prevention of dementia should be prioritized by clinicians and healthcare policy, and by more ambitious research efforts. In particular, the public health message that cognitive decline and dementia are preventable should be reinforced among both clinicians and patients.

\section{Abbreviations \\ ACE: Angiotensin-converting enzyme; AD: Alzheimer's disease; ADHD: Attention deficit hyperactivity disorder; APOE: Apolipoprotein E; BMl: Body mass index; Cl: Confidence interval; GP: General practitioner; IQ: Intelligence quotient; NSAID: Non-steroidal anti-inflammatory drug; RR: Relative risk; VaD: Vascular dementia.}

\section{Competing interests}

$\mathrm{JHB}$ and $\mathrm{ADB}$ are employees of, and own shares in, Cambridge Cognition. $\mathrm{VH}$ declares no competing interests.

\section{Authors' contributions}

ADB and JHB conceived the basis of the article, based in part on discussions with $\mathrm{VH}$ who subsequently contributed additional ideas and critical input. $J H B$ drafted the initial manuscript and figures, incorporating contributions from all authors. All authors read and approved the final manuscript.

\section{Author details}

'Department of Psychiatry, University of Cambridge, Cambridge Biomedical Campus, Cambridge, CB2 2QQ, UK. ${ }^{2}$ Cambridge Cognition Ltd, Tunbridge Court, Tunbridge Lane, Bottisham, CB25 9TU, UK. ${ }^{3}$ Department of Clinical Neurological Sciences, London Health Sciences Centre, University of Western Ontario, University Hospital, 339 Windermere Road, London, Ontario, N6A 5A5, Canada.

Received: 16 August 2013 Accepted: 22 October 2013 Published: 19 Nov 2013

\section{References}

1. Wimo A, Prince M: World Alzheimer Report 2010: The Global Economic Impact of Dementia. Alzheimer's Disease International: London, UK; 2010.

2. National Collaborating Centre for Mental Health: Dementia: a NICE-SCIE Guideline on Supporting People with Dementia and Their Carers in Health and Social Care. London, UK: The British Psychological Society; 2007.

3. Snowdon DA, Greiner LH, Mortimer JA, Riley KP, Greiner PA, Markesbery WR: Brain infarction and the clinical expression of Alzheimer disease. The Nun Study. JAMA 1997, 277:813-817.

4. Pathological correlates of late-onset dementia in a multicentre, community-based population in England and Wales. Neuropathology Group of the Medical Research Council Cognitive Function and Ageing Study (MRC CFAS). Lancet 2001, 357:169-175.

5. Schneider JA, Arvanitakis Z, Bang W, Bennett DA: Mixed brain pathologies account for most dementia cases in community-dwelling older persons. Neurology 2007, 69:2197-2204.

6. Provenzano FA, Muraskin J, Tosto G, Narkhede A, Wasserman BT, Griffith EY, Guzman VA, Meier IB, Zimmerman ME, Brickman AM: White matter hyperintensities and cerebral amyloidosis: necessary and sufficient for clinical expression of Alzheimer disease? JAMA Neurol 2013, 70:455-461.

7. Marchant NL, Reed BR, Sanossian N, Madison CM, Kriger S, Dhada R, Mack WJ, Decarli C, Weiner MW, Mungas DM, Chui HC, Jagust WJ: The aging brain and cognition: contribution of vascular injury and $A \beta$ to mild cognitive dysfunction. JAMA Neurol 2013, 70:488-495.
8. Toledo JB, Arnold SE, Raible K, Brettschneider J, Xie SX, Grossman M, Monsell SE, Kukull WA, Trojanowski JQ: Contribution of cerebrovascular disease in autopsy confirmed neurodegenerative disease cases in the National Alzheimer's Coordinating Centre. Brain 2013, 136:2697-2706.

9. Quinn JF, Raman R, Thomas RG, Yurko-Mauro K, Nelson EB, Van Dyck C, Galvin JE, Emond J, Jack CR, Weiner M, Shinto L, Aisen PS: Docosahexaenoic acid supplementation and cognitive decline in alzheimer disease: a randomized trial. JAMA 2010, 304:1903-1911.

10. Schor NF: What the halted phase III $\gamma$-secretase inhibitor trial may (or may not) be telling us. Ann Neurol 2011, 69:237-239.

11. Miller G: Pharmacology. The puzzling rise and fall of a dark-horse Alzheimer's drug. Science 2010, 327:1309.

12. Lobo A, Launer LJ, Fratiglioni L, Andersen K, Di Carlo A, Breteler MM Copeland JR, Dartigues JF, Jagger C, Martinez-Lage J, Soininen H, Hofman A: Prevalence of dementia and major subtypes in Europe: a collaborative study of population-based cohorts. Neurologic diseases in the Elderly Research Group. Neurology 2000, 54:S4-S9.

13. Bertram L, Tanzi RE: Thirty years of Alzheimer's disease genetics: the implications of systematic meta-analyses. Nat Rev Neurosci 2008, 9:768-778.

14. Yin Y-W, Li J-C, Wang J-Z, Li B-H, Pi Y, Yang Q-W, Fang C-Q, Gao C-Y, Zhang $\mathrm{L}-\mathrm{L}$ : Association between apolipoprotein $\mathrm{E}$ gene polymorphism and the risk of vascular dementia: a meta-analysis. Neurosci Lett 2012, 514:6-11.

15. Rockwood K, Ebly E, Hachinski V, Hogan D: Presence and treatment of vascular risk factors in patients with vascular cognitive impairment. Arch Neuro 1997, 54:33-39.

16. Barnes DE, Yaffe K: The projected effect of risk factor reduction on Alzheimer's disease prevalence. Lancet Neurol 2011, 10:819-828.

17. Xu WL, Atti AR, Gatz M, Pedersen NL, Johansson B, Fratiglioni L: Midlife overweight and obesity increase late-life dementia risk: a population-based twin study. Neurology 2011, 76:1568-1574.

18. Tolppanen A-M, Solomon A, Soininen $H$, Kivipelto M: Midlife vascular risk factors and Alzheimer's disease: evidence from epidemiological studies. J Alzheimers Dis 2012, 32:531-540.

19. Kivipelto M, Ngandu T, Fratiglioni L, Viitanen M, Kåreholt I, Winblad B, Helkala E-L, Tuomilehto J, Soininen H, Nissinen A: Obesity and vascular risk factors at midlife and the risk of dementia and Alzheimer disease. Arch Neurol 2005, 62:1556-1560.

20. Qiu C: Preventing Alzheimer's disease by targeting vascular risk factors: hope and gap. J Alzheimers Dis 2012, 32:721-731.

21. Sofi F, Abbate R, Gensini GF, Casini A: Accruing evidence about benefits of adherence to the Mediterranean diet on health: an updated systematic review and meta-analysis. Am J Clin Nutr 2010, 92:1189-1196.

22. Hamer M, Chida Y: Physical activity and risk of neurodegenerative disease: a systematic review of prospective evidence. Psychol Med 2009, 39:3-11.

23. Orozco $\sqcup$, Buchleitner AM, Gimenez-Perez G, Roqué I, Figuls M, Richter B, Mauricio D: Exercise or exercise and diet for preventing type 2 diabetes mellitus. Cochrane Database Syst Rev 2008, 3:CD003054.

24. Sofi F, Capalbo A, Cesari F, Abbate R, Gensini GF: Physical activity during leisure time and primary prevention of coronary heart disease: an updated meta-analysis of cohort studies. Eur J Cardiovasc Prev Rehabil 2008, 15:247-257.

25. Peila R, White LR, Petrovich H, Masaki K, Ross GW, Havlik RJ, Launer L: Joint effect of the APOE gene and midlife systolic blood pressure on late-life cognitive impairment: the Honolulu-Asia aging study. Stroke 2001, 32:2882-2889.

26. Rodrigue KM, Rieck JR, Kennedy KM, Devous MD Sr, Diaz-Arrastia R, Park DC: Risk factors for $\beta$-amyloid deposition in healthy aging: vascular and genetic effects. JAMA Neurol 2013, 70:600-606.

27. Tzourio C, Anderson C, Chapman N, Woodward M, Neal B, MacMahon S, Chalmers J: Effects of blood pressure lowering with perindopril and indapamide therapy on dementia and cognitive decline in patients with cerebrovascular disease. Arch Intern Med 2003, 163:1069-1075.

28. Aisen PS, Schafer KA, Grundman M, Pfeiffer E, Sano M, Davis KL, Farlow MR, Jin S, Thomas RG, Thal LJ: Effects of rofecoxib or naproxen vs placebo on Alzheimer disease progression: a randomized controlled trial. JAMA 2003, 289:2819-2826.

29. Isaac MG, Quinn R, Tabet N: Vitamin E for Alzheimer's disease and mild cognitive impairment. Cochrane Database Syst Rev 2008, 3:CD002854.

30. Malouf R, Grimley Evans J: Folic acid with or without vitamin B12 for the prevention and treatment of healthy elderly and demented people. Cochrane Database Syst Rev 2008, 4:CD004514. 
31. de Boo HA, Harding JE: The developmental origins of adult disease (Barker) hypothesis. Aust NZ J Obstet Gynecol 2006, 46:4-14.

32. Brion M-JA, Lawlor DA, Matijasevich A, Horta B, Anselmi L, Araújo CL, Menezes AMB, Victora CG, Davey Smith G: What are the causal effects of breastfeeding on IQ, obesity and blood pressure? Evidence from comparing high-income with middle-income cohorts. Int J Epidemiol 2011, 40:670-680.

33. Isaacs EB, Gadian DG, Sabatini S, Chong WK, Quinn BT, Fischl BR, Lucas A: The effect of early human diet on caudate volumes and IQ. Pediatr Res 2008, 63:308-314.

34. Strauss RS: Adult functional outcome of those born small for gestational age: twenty-six-year follow-up of the 1970 British Birth Cohort. JAMA 2000, 283:625-632.

35. Huang TL, Carlson MC, Fitzpatrick AL, Kuller LH, Fried LP, Zandi PP: Knee height and arm span: a reflection of early life environment and risk of dementia. Neurology 2008, 70:1818-1826.

36. Katzman R, Terry R, DeTeresa R, Brown T, Davies P, Fuld P, Renbing X, Peck A: Clinical, pathological, and neurochemical changes in dementia: a subgroup with preserved mental status and numerous neocortical plaques. Ann Neuro 1988, 23:138-144.

37. Power $C$, Atherton $K$, Thomas C: Maternal smoking in pregnancy, adult adiposity and other risk factors for cardiovascular disease. Atherosclerosis 2010, 211:643-648.

38. Anstey KJ, Cherbuin N, Budge M, Young J: Body mass index in midlife and late-life as a risk factor for dementia: a meta-analysis of prospective studies. Obes Rev 2011, 12:e426-e437.

39. Gustafson D: A life course of adiposity and dementia. Eur J Pharmacol 2008, 585:163-175.

40. Moffitt TE, Arseneault L, Belsky D, Dickson N, Hancox RJ, Harrington $H_{\text {, }}$ Houts R, Poulton R, Roberts BW, Ross S, Sears MR, Thomson WM, Caspi A: A gradient of childhood self-control predicts health, wealth, and public safety. Proc Natl Acad Sci U S A 2011, 108:2693-2698.

41. Valenzuela MJ, Sachdev P: Brain reserve and dementia: a systematic review. Psychol Med 2006, 36:441-454.

42. Sharpbrains: Web-based, Mobile and Biometrics-Based Technology to Assess, Monitor and Enhance Cognition and Brain Function. [http://sharpbrains.com/market-report/]

43. Ahmad S, Orrell M, lliffe S, Gracie A: GPs' attitudes, awareness, and practice regarding early diagnosis of dementia. Br J Gen Pract 2010, 60:e360-365.

44. Richard E, Andrieu S, Solomon A, Mangialasche F, Ahtiluoto S, van Charante EPM, Coley N, Fratiglioni L, Neely AS, Vellas B, van Gool WA, Kivipelto M: Methodological challenges in designing dementia prevention trials - The European Dementia Prevention Initiative (EDPI). J Neurol Sci 2012, 322:64-70.

\subsection{6/1741-7015-11-246}

Cite this article as: Barnett et al:: Cognitive health begins at conception: addressing dementia as a lifelong and preventable condition. $B M C$ Medicine 2013, 11:246

\section{Submit your next manuscript to BioMed Central and take full advantage of:}

- Convenient online submission

- Thorough peer review

- No space constraints or color figure charges

- Immediate publication on acceptance

- Inclusion in PubMed, CAS, Scopus and Google Scholar

- Research which is freely available for redistribution 